Tema: Aciaria Oxigênio

\title{
COMPARAÇÃO DA PENETRAÇÃO DO SOPRO DE OXIGÊNIO EM CONVERTEDORES BOF COM BICOS MULTIFUROS UTILIZANDO MODELAGEM FÍSICA*
}

\author{
Ana Clara Petrucelli ${ }^{1}$ \\ Breno Totti Maia² \\ Caio Nogueira Araújo Diniz ${ }^{1}$ \\ Débora Silveira ${ }^{1}$ \\ Pedro Henrique Marques Spínola de Andrade ${ }^{1}$ \\ Rafael Kajimoto Imagawa ${ }^{1}$ \\ Roberto Parreiras Tavares ${ }^{3}$
}

\section{Resumo}

A principal ferramenta de controle do processo BOF reside na regulagem do sopro de oxigênio. A análise dos parâmetros de interação entre o sopro e o banho metálico compõe o objetivo deste trabalho. Através de uma análise visual da penetração e fração volumétrica da bacia de descarburação, foi determinada a melhor configuração de sopro entre diferentes combinações de bicos multifuros (3 a 6 furos), distância lança-banho e vazão. Foram feitas previsões sobre a penetração do jato a partir de um balanço de energia a fim de validá-las com o modelo físico. As maiores penetrações foram alcançadas com os bicos de 3 e 4 furos, com a maior vazão e menor distância lança-banho dentre os padrões testados. Todavia, as maiores frações volumétricas da bacia de descarburação foram obtidas com 5 e 6 furos, vazão e distâncias variadas dentre as ensaiadas.

Palavras-chaves: BOF; Penetração de jato; Bacia de descarburação; Froude; Modelo físico.

\section{COMPARISON OF JET PENETRATION OXYGEN BLOW IN BOF CONVERTER WITH MULTIHOLES TIPS BY PHYSICAL MODE}

\section{Abstract}

The primary control tool of the BOF process lies on the oxygen blow adjustment. The analysis of interaction parameters between oxygen blow and molten metal is objective of this work. Through visual inspection, jet penetration and volume fraction of decarburization region, the best configuration of oxygen blow was determined among different sets of nozzles, lance heights and gas flow rates. Predictions of jet penetration were made using an energy balance in order to validate them with physical model results. The deeper penetrations were reached using three and four hole nozzles, highest flow e smallest lance height among configurations tested. However, the biggest volume fractions of decarburization region were obtained using five and six holes nozzles, varied lance height and gas flow rates.

Keywords: BOF; Jet penetration, Decarburization region; Froude number; Physical model.

Aluno de Graduação, Engenharia Metalúrgica, UFMG, Belo Horizonte, MG, Brasil.

Engenheiro Metalurgista, Doutor Pesquisador, Lumar Metals, sócio da ABM, Belo Horizonte, MG, Brasil.

3 Engenheiro Metalurgista, Professor Doutor, Departamento de Engenharia Metalúrgica, UFMG, Sócio da ABM, Belo Horizonte, MG, Brasil.

* Contribuição técnica ao 450 Seminário de Aciaria - Internacional, 25 a 28 de maio de 2014, 


\section{INTRODUÇÃO}

O processo do convertedor BOF exibe características de alta produtividade, custos adequados e grande flexibilidade metalúrgica, sendo possível a fabricação de vasta gama de tipos de aços. O oxigênio injetado a altas pressões atinge o banho de gusa e dá início a uma série de reações de combustão, entretanto, aquela que é primariamente objetivada é a queima do carbono, que retira seu excesso do gusa a fim de ajustar a composição do banho em uma faixa que permite dar ao produto o nome de aço. Neste processo, é utilizado sopro supersônico de oxigênio. A configuração do sistema de injeção e a vazão de oxigênio tem efeito significativo sobre a evolução da reação de descarburação [1].

As primeiras lanças de injeção de oxigênio nos convertedores apresentavam bico com apenas um furo central, do tipo paralelo ou convergente-divergente. Entretanto, o aumento da capacidade dos convertedores trouxe a necessidade do aumento da vazão de oxigênio para que fosse mantido o tempo de sopro [2]. Isto levou a utilização de diâmetros de furo e vazões cada vez maiores, o que causou aumento das anormalidades operacionais, como, por exemplo, o excesso de penetração de jato que aumentava o desgaste do revestimento do refratário. $O$ desenvolvimento dos bicos multifuros possibilitou a eliminação deste problema.

A interação do jato de oxigênio com o banho metálico pode ser definida basicamente por dois parâmetros: a profundidade de penetração e o diâmetro da depressão formada na superfície, conforme exemplificado pela Figura 1, sendo o primeiro parâmetro um fator influenciado principalmente pela energia contida no jato (pressão, velocidade, etc.) e o segundo pelo diâmetro do sopro no nível do banho (diâmetro e inclinação dos furos, altura de sopro, etc.) [3].

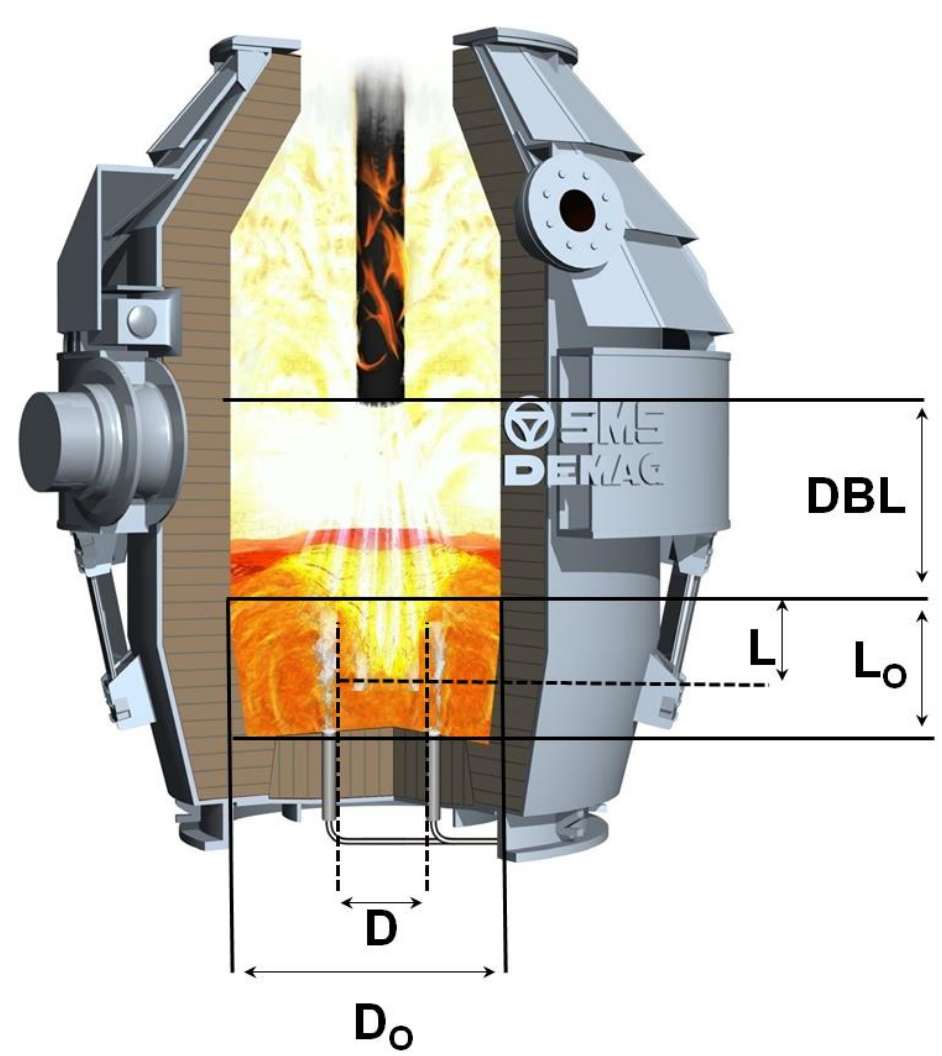

L=Penetração do jato de oxigênio

no banho metálico;

Lo=Profundidade do banho

estático;

D=Diâmetro do banho;

Do=Diâmetro da penetração do jato

DBL=Distância Banho Lança

Figura 1. Deformação do banho formado pelo impacto do jato (Adaptado Odenthal) [4].

* Contribuição técnica ao $45^{\circ}$ Seminário de Aciaria - Internacional, 25 a 28 de maio de 2014, 
Como a principal ferramenta de controle do processo BOF reside na regulagem do sopro de oxigênio, os parâmetros que determinam sua interação com o banho são a motivação para este estudo. A relevância deste trabalho concerne ao dimensionamento da bacia de descarburação e do impacto causado pela penetração do jato sobre as paredes do reator. O primeiro tópico tem reflexo direto na redução do tempo de sopro do reator e na qualidade do aço produzido, estes, intimamente relacionados aos fenômenos de mistura, homogeneidade e uniformidade térmica. $O$ segundo, por sua vez, é um indicativo do possível desgaste mecânico causado por determinadas configurações de sopro sobre o revestimento refratário, sendo determinante sobre a vida útil deste componente [5]. Buscou-se estabelecer um paralelo entre os resultados teóricos obtidos através de um modelo matemático e a verificação prática da penetração do jato superior em um modelo físico a temperatura ambiente do convertedor BOF. Foram feitos ensaios sob diferentes combinações de vazão, distância lança-banho e número de furos no bico da lança.

\section{METODOLOGIA}

Os experimentos foram realizados no Laboratório de Simulação de Processos (LaSIP), que se encontra no departamento de engenharia metalúrgica e materiais (DEMET-UFMG). A partir de um modelo físico construído em acrílico, cujas dimensões estão especificadas na Figura 2, foram feitos os experimentos a temperatura ambiente, usando água (fluido simulador do aço) e ar comprimido (simulando o oxigênio) [6].

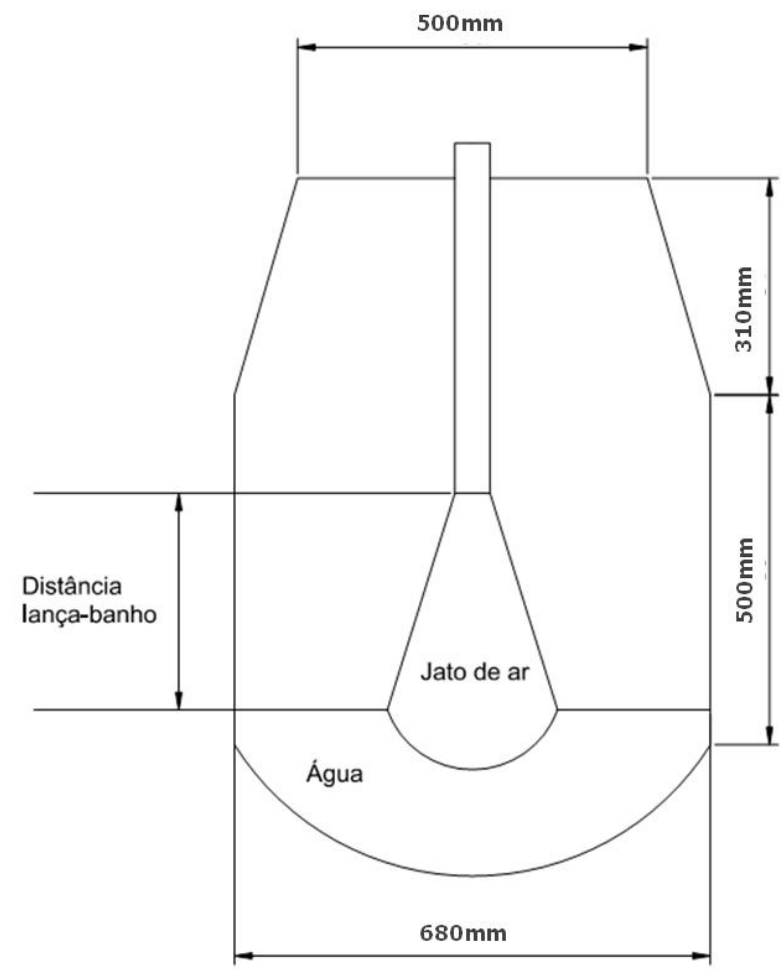

Figura 2. Dimensionamento do modelo físico do convertedor BOF (LaSIP-UFMG).

Para realização dos ensaios, o vaso foi preenchido com água na altura que representa o nível do banho metálico. Os bicos de lança foram conectados na saída

* Contribuição técnica ao $45^{\circ}$ Seminário de Aciaria - Internacional, 25 a 28 de maio de 2014, 
do sistema de ar comprimido. Para alimentar o sistema com ar comprimido foi utilizado um compressor 22,5kW, capaz de fornecer 7,87x105Pa de pressão máxima e uma vazão máxima de $189 \mathrm{~m}^{3} / \mathrm{h}$. Este modelo físico representa um convertedor BOF de 220 toneladas e corresponde às condições de operação para relação volume sobre carga de $0,63 \mathrm{~m}^{3} / \mathrm{t}$. Esta relação consiste na divisão do volume do convertedor em metros cúbicos pela carga total enfornada em toneladas. O modelo foi construído na escala de 1/8 do modelo industrial. A Figura 3 ilustra o vaso em acrílico conectado ao compressor que foi usado nos experimentos.

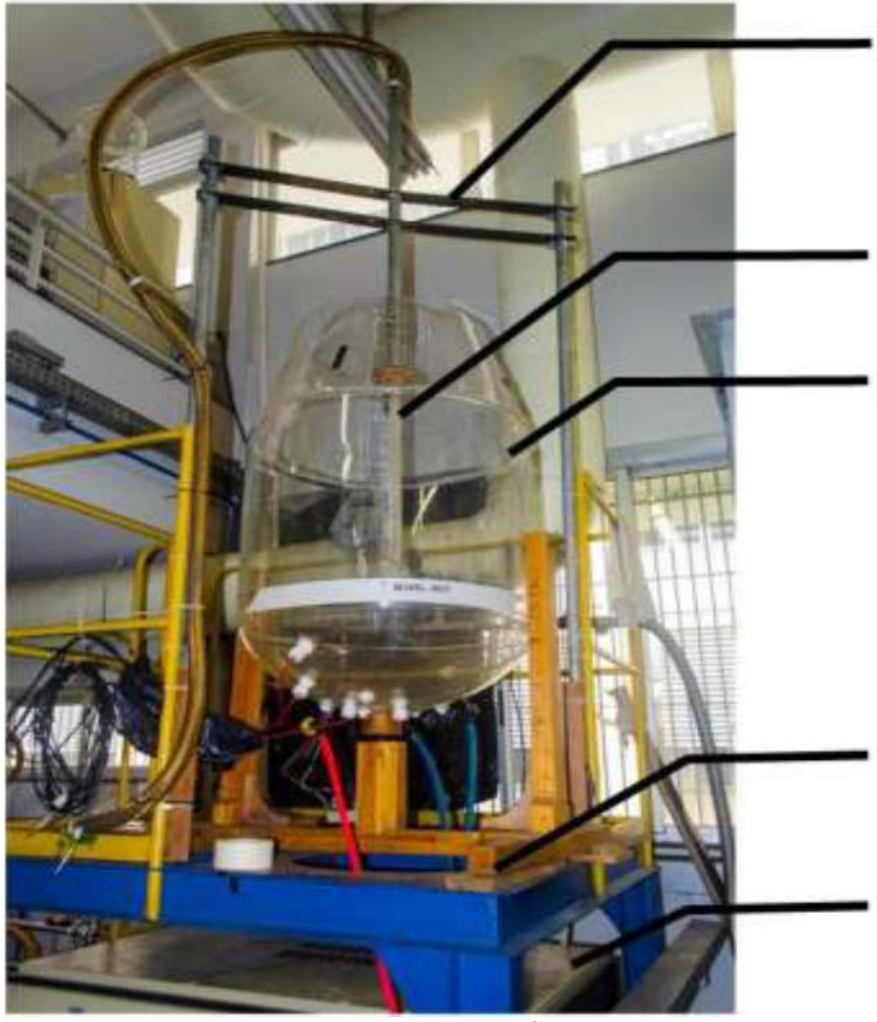

Figura 3. Foto do modelo físico do convertedor BOF (LaSIP-UFMG).

\section{Plataforma}

\section{Compressor}

\section{Suporte da \\ lança}

Lança e Bico de

Resina Acrilica

Convertedor LD

O emprego da água como fluido de simulação do aço líquido é justificado pelos valores viscosidades cinemáticas próximos dos dois fluidos. Esta e outras propriedades destes dois fluidos estão evidenciadas na Tabela 1.

Tabela 1. Comparação entre as propriedades do aço e da água [6, 7]

\begin{tabular}{c|c|c|c|c}
\hline Propriedade & Unidade & Símbolo & Água & Aço \\
\hline Temperatura & ${ }^{\circ} \mathrm{C}$ & $\mathrm{T}$ & 25 & 1600 \\
\hline Viscosidade dinâmica & $\mathrm{kg} \cdot \mathrm{m}^{-1} \cdot \mathrm{s}^{-1}$ & $\mu$ & $1,0 \times 10^{-3}$ & $6,4 \times 10^{-3}$ \\
\hline Viscosidade cinemática & $\mathrm{m}^{2} \cdot \mathrm{s}^{-1}$ & $v$ & $1,00 \times 10^{-6}$ & $9,13 \times 10^{-1}$ \\
\hline Densidade & $\mathrm{kg} \cdot \mathrm{m}^{-3}$ & $\rho$ & $1,00 \times 10^{3}$ & $7,08 \times 10^{3}$ \\
\hline Tensão Superficial & $\mathrm{N} \cdot \mathrm{m}^{-1}$ & $\sigma$ & 0,0728 & 1,600 \\
\hline
\end{tabular}

Os experimentos se basearam na variação de três parâmetros do sistema presente na Figura 3, que foram: vazão $\left(100 \mathrm{~m}^{3} / \mathrm{h}, 130 \mathrm{~m}^{3} / \mathrm{h}\right.$ e $\left.160 \mathrm{~m} 3 / \mathrm{h}\right)$, distancia banho-

* Contribuição técnica ao $45^{\circ}$ Seminário de Aciaria - Internacional, 25 a 28 de maio de 2014, 
lança $(118 \mathrm{~mm}, 180 \mathrm{~mm}$ e $250 \mathrm{~mm})$ e número de furos presentes nos bicos $(3,4,5$ e 6 furos com ângulos respectivamente de $7^{\circ}, 8^{\circ}, 15^{\circ}$ e $\left.17,5^{\circ}\right)$, ilustrados na Figura 4.

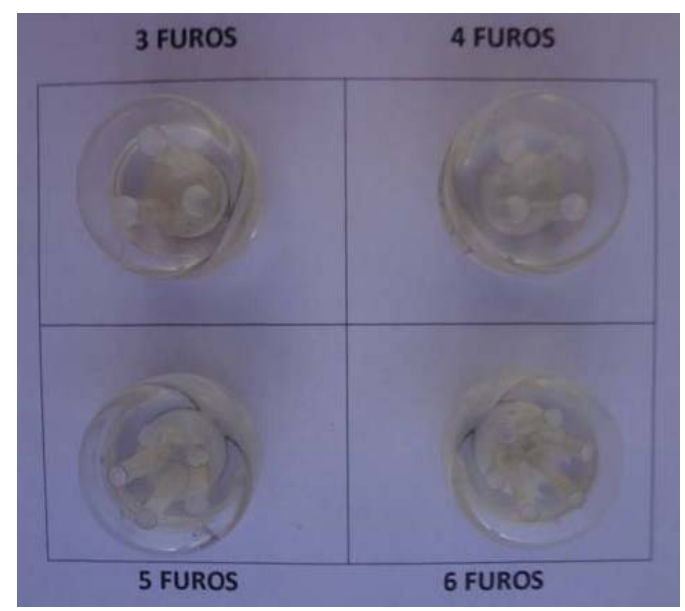

(a)

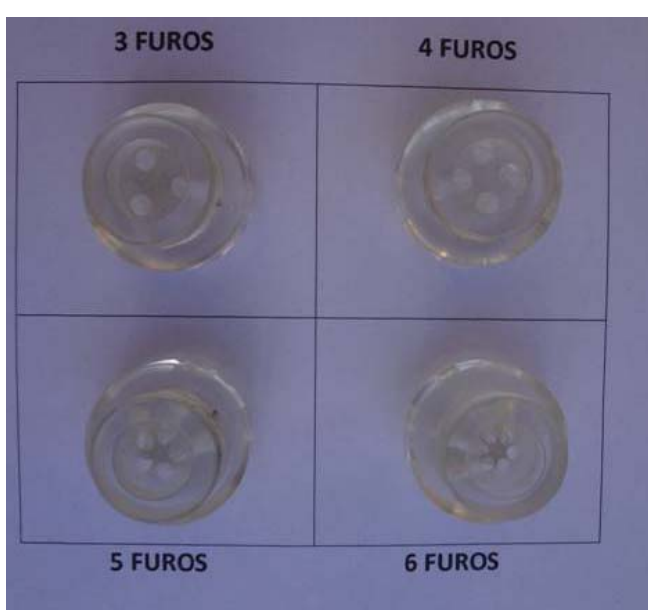

(b)

Figura 4. Bicos multifuros testados nos ensaios: (a) vista frontal e (b) vista traseira.

Foram realizados experimentos varrendo todas as combinações dentre estes três parâmetros. As medidas de penetração do jato de ar no banho, foram feitas a partir de filmagens dos experimentos juntamente com o uso do software Image $₫$, que possibilitou a estimativa de valores de penetrações, feito segundo o exemplo da Figura 5.

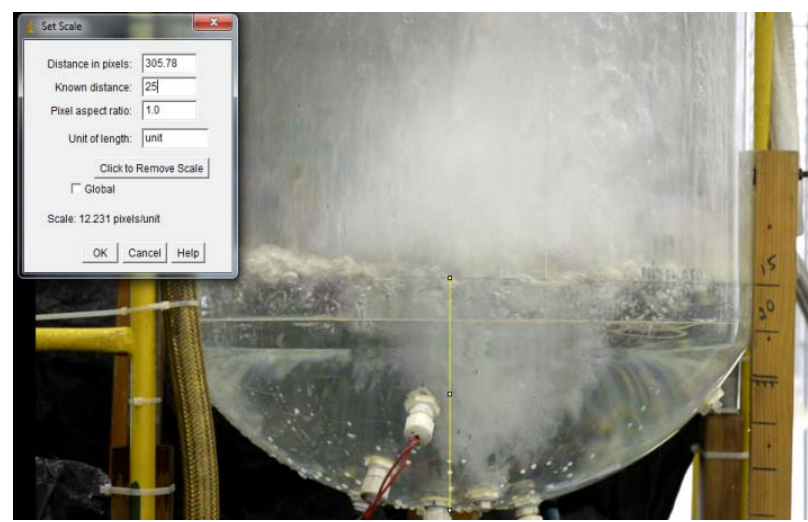

Figura 5. Exemplo de estimativa de penetração a partir da distancia conhecida do nível de água no vaso usando o software Image ${ }^{\circledR}$.

A Figura 5 ilustra o momento da filmagem em que é feita à estimativa do valor de penetração a partir de uma medida conhecida, que no caso é o nível de água presente no vaso $(25 \mathrm{~cm}$ de altura). Para o cálculo dos valores teóricos de penetração no banho foi correlacionados a quantidade de movimento do jato através de um balanço de energia na base da cavidade, correlacionado com o número modificado de Froude, conforme a adequação das equações desenvolvidas por Szekely [8], Meidani et al. [2] e Alam et al. [9-11], proposta por Maia [3]:

$$
\frac{\pi \times \rho_{g} \times V_{s}^{2} \times D_{s}^{2} \times \cos \theta \times n}{4 \times \rho_{l} \times g \times H^{3}}=\frac{\pi}{2 \times K^{2}} \times \frac{P}{H}\left(1+\frac{P}{H \times \cos \theta}\right)^{2}
$$

Onde " $\rho$ " - densidade na saída do bocal $\left(\mathrm{kg} \cdot \mathrm{m}^{-3}\right), " \rho$ " - densidade do banho $\left(\mathrm{kg} \cdot \mathrm{m}^{-3}\right)$, "g" - aceleração da gravidade $\left(\mathrm{m}^{\mathrm{s}} \mathrm{s}^{-2}\right)$, "P" - Penetração (m), "H" - Distância

* Contribuição técnica ao 45 Seminário de Aciaria - Internacional, 25 a 28 de maio de 2014, Porto Alegre, RS, Brasil. 


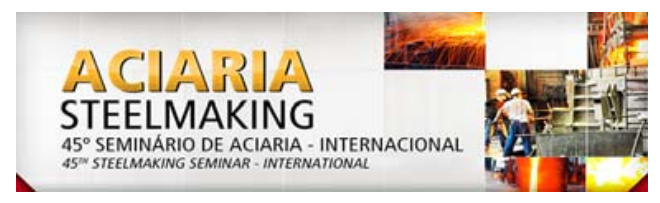

da lança ao banhou ou DBL $(m)$, "K" - uma constante empírica para cada tipo de bico, " $\theta$ " - ângulo de cada um dos furos dos bicos com a vertical, "n" - número de furos do bico.

A partir do software Image $₫ \circledR$ também foi feita uma estimativa da área superficial da bacia de descarburação formada onde há contato direto entre o jato e o banho. Juntamente com o valor de penetração, a área estimada pode ser de grande valor para a definição de uma instalação ótima ao processo.

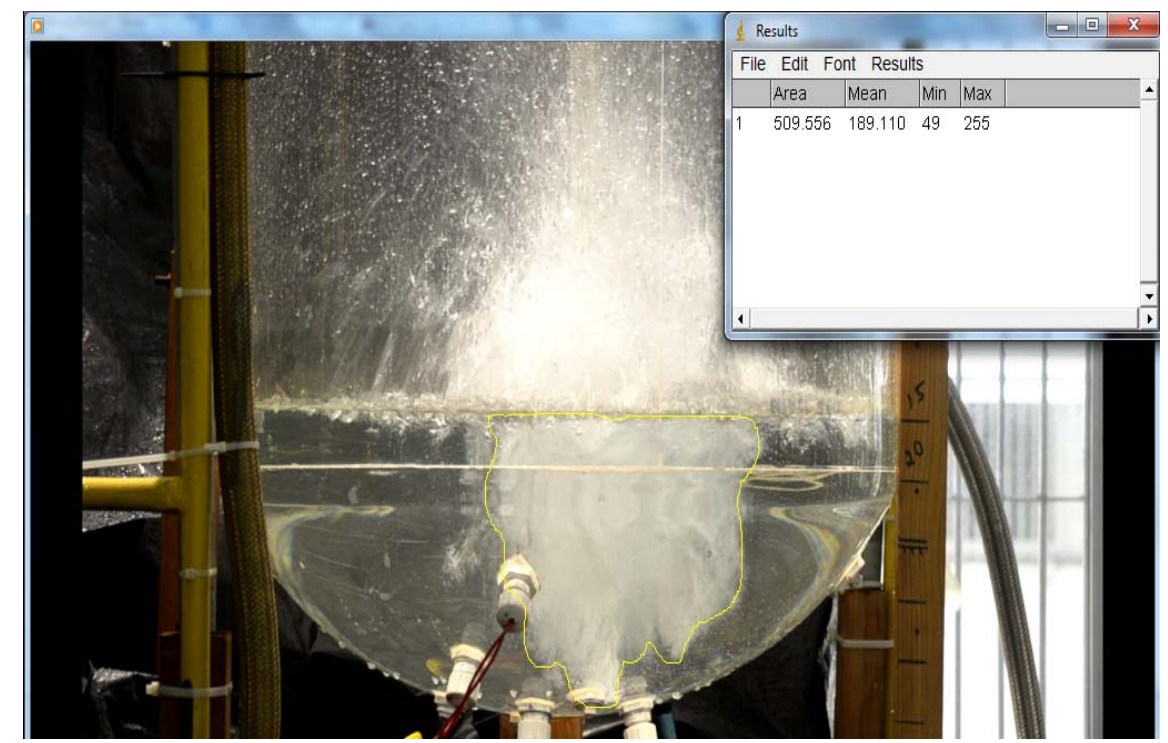

Figura 6. Exemplo de estimativa de área de mistura usando o software Imagej ${ }^{\circledR}$.

A penetração foi calculada utilizando a Equação 1. As medidas realizadas no modelo físico foram feitas considerando o instante de penetração máxima das filmagens e medindo a imagem capturada com o software Image $₫$, conforme ilustrado na Figura 6. As filmagens foram iniciadas na situação em que o banho estava estático, e a vazão e altura de lança já haviam sido estabelecidas. Com o sistema pressurizado, a válvula de abertura era liberada e o jato atingia o banho diretamente nas condições pré-estabelecidas. O ensaio prosseguia até que o nível de turbidez da água impossibilitasse a visualização da penetração do jato. Neste instante interrompia-se a filmagem.

\section{RESULTADOS E DISCUSSÃO}

\subsection{Avaliação da Penetração do Jato}

As medidas feitas a partir das imagens capturadas foram então sobrepostas aos valores calculados em gráficos representando cada uma das configurações testadas (vazão, DBL, número de furos). Nos gráficos, o eixo das abcissas representa a distância lança-banho medida em metros $(0,117 \mathrm{~m} ; 0,180 \mathrm{~m} ; 0,250 \mathrm{~m})$ e o eixo das ordenadas representa a altura da coluna de água que separa o jato do fundo do convertedor, sendo que o valor zero indica que o jato tocou o fundo, e um valor de $0,25 \mathrm{~m}$ indicaria que o jato não penetrou o banho. Valores negativos, presentes na série de dados calculados pelo balanço de energia, representam situações teorizadas em que o jato alcançaria o fundo do modelo de maneira mais agressiva.

A série de dados representada com quadrados negros são valores medidos e a série representada por quadrados claros são valores calculados em todos os gráficos a

* Contribuição técnica ao 45 Seminário de Aciaria - Internacional, 25 a 28 de maio de 2014, Porto Alegre, RS, Brasil. 
seguir. A medida de penetração foi determinada por três avaliadores de forma independente. Os valores representados nas figuras são as médias e as barras de desvio-padrão.

\section{Furos $7^{\circ}$ Vertical}
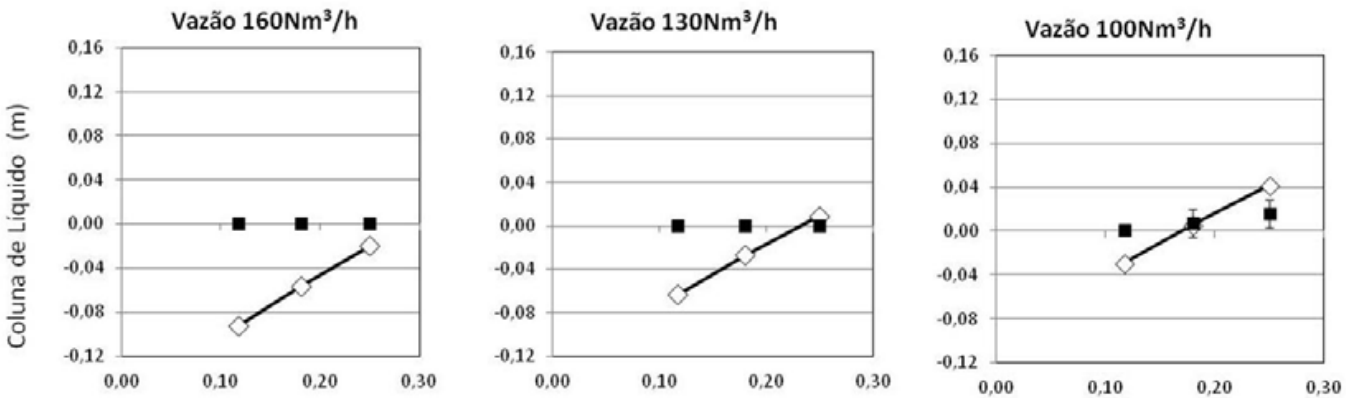

Figura 7. Vazão x penetração para bico de 3 furos e $7^{\circ}$ com relação a vertical.

\section{Furos $12^{\circ}$ Vertical}
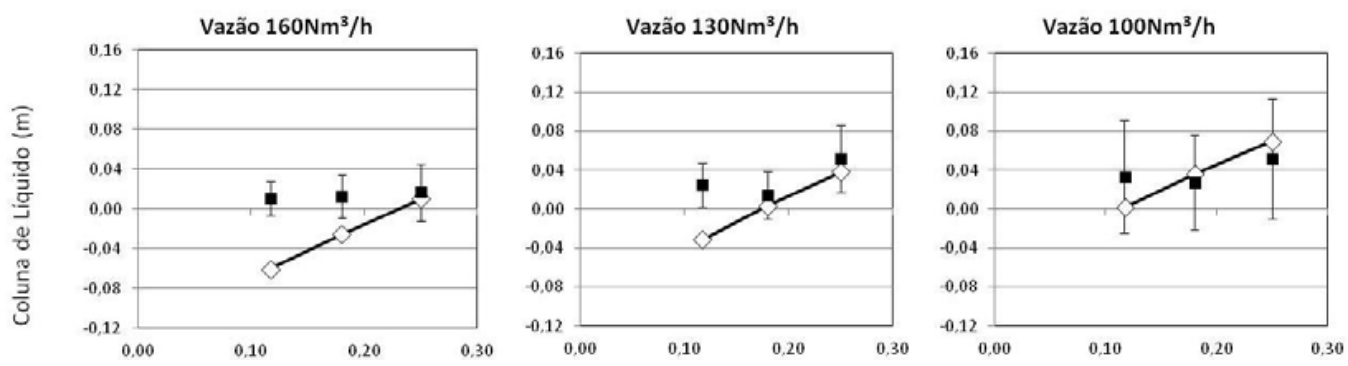

Figura 8. Vazão x penetração para bico de 4 furos e $12^{\circ} \mathrm{com}$ relação a vertical.

\section{Furos $15^{\circ}$ Vertical}
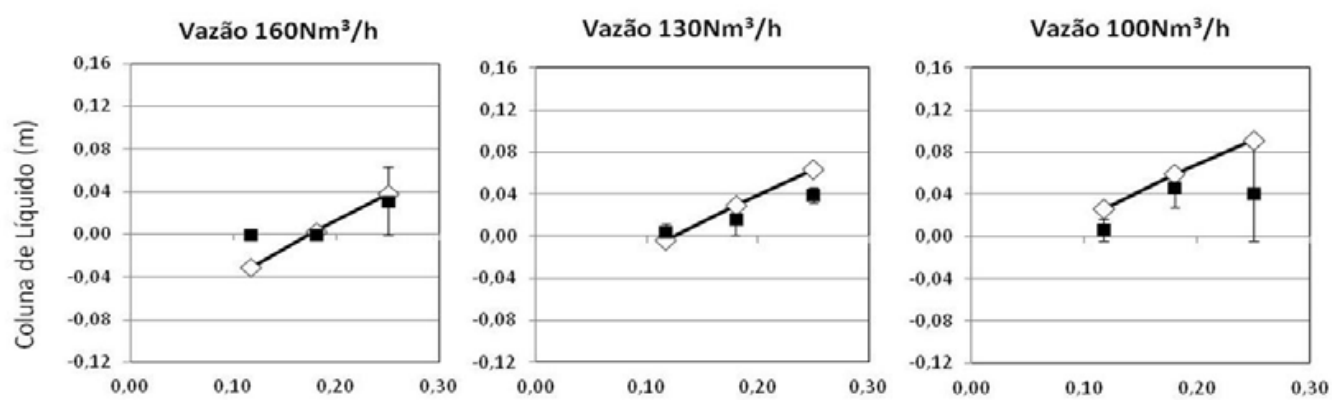

Figura 9. Vazão x penetração para bico de 5 furos.

\section{Furos $17,5^{\circ}$ Vertical}
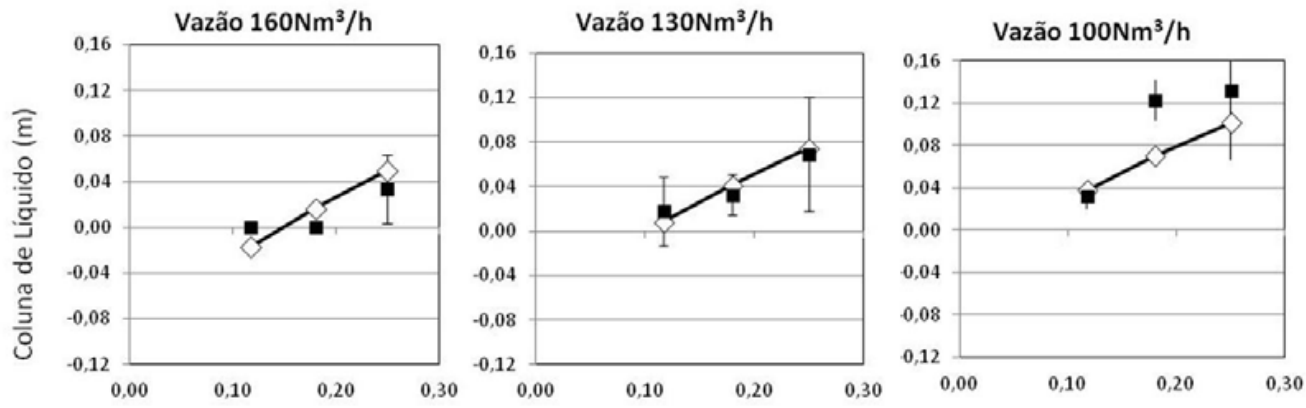

Figura 10. Vazão x penetração para bico de 6 furos.

* Contribuição técnica ao 450 Seminário de Aciaria - Internacional, 25 a 28 de maio de 2014, Porto Alegre, RS, Brasil. 


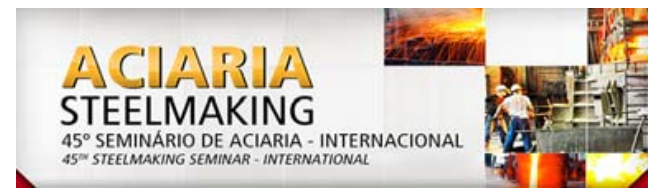

Para a vazão máxima de $160 \mathrm{Nm}^{3} / \mathrm{h}$ apenas a configuração que utiliza 6 furos e maior $\operatorname{DBL}(0,25 \mathrm{~m})$ não alcançou o fundo do modelo. Isto mostra que vazões elevadas tendem a causar maior desgaste do refratário presente no equipamento, mesmo entre a diversidade de condições de vazão e DBL ensaiadas. Com as vazões de $130 \mathrm{Nm}^{3} / \mathrm{h}$ e $100 \mathrm{Nm}^{3} / \mathrm{h}$ o efeito dos demais parâmetros torna-se mais pronunciado sobre o resultado final da penetração. Analisando o efeito da distância banho-lança, foram obtidas as maiores penetrações para o menor DBL $(0,117 \mathrm{~m})$ dentre as variações de número de furos e vazão. Avaliando-se os resultados teóricos, tem-se uma tendência de diminuição da penetração com o aumento do número de furos, ou seja, para bicos de 3 e 4 furos, para os quais o jato é mais concentrado, a penetração calculada alcançou os valores mais negativos, enquanto para os bicos de 5 e 6 furos, nos quais o jato é mais distribuído, a penetração calculada não alcançou os mesmos níveis. Verifica-se uma correspondência entre as duas séries de valores, calculados e medidos, de forma que ambas seguem uma mesma tendência de diminuição da penetração com o aumento do DBL, diminuição da vazão e aumento do número de furos. As condições que se desviaram dessa consonância se concentraram naquelas com vazão mínima $(100 \mathrm{Nm} 3 / \mathrm{h})$. A partir da Equação 1 e de posse dos parâmetros de sopro utilizados foram determinados os números de Froude modificado, correspondente ao lado esquerdo da equação, e a penetração adimensional, correspondente ao lado direito da equação, evidenciando o fator $1 / \mathrm{K}^{2}$.
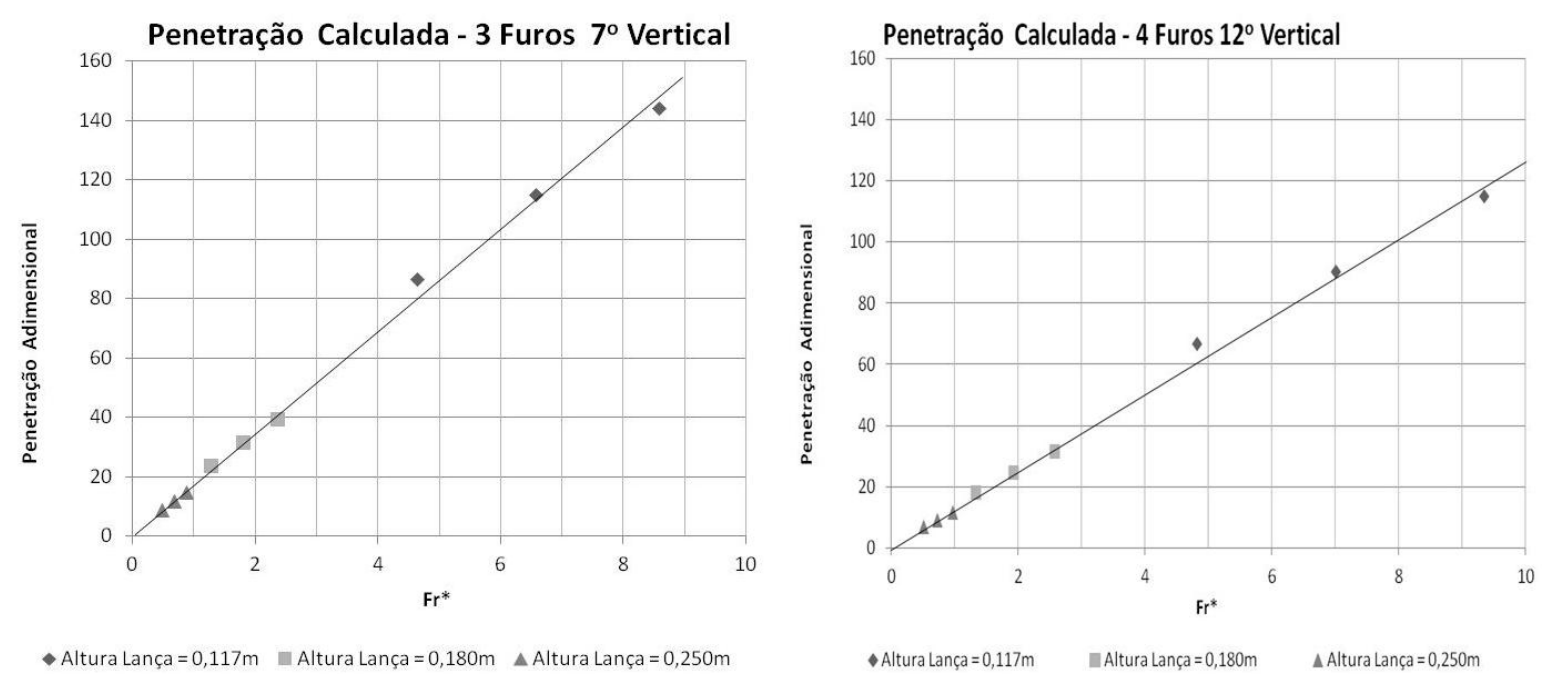

Figura 11. Penetração adimensional versus Froude modificado para bicos de 3 e 4 furos, vazões de $100 \mathrm{Nm}^{3} / \mathrm{h}, 130 \mathrm{Nm}^{3} / \mathrm{h}$ e $160 \mathrm{Nm}^{3} / \mathrm{h}$ e DBL de $0,110 \mathrm{~m}, 0,180 \mathrm{~m}, 0,250 \mathrm{~m}$.

Os valores obtidos para cada uma das configurações de sopro foram comparados em gráficos e correlacionados através de regressão linear para avaliar o coeficiente angular, cuja raiz quadrada representa a constante empírica "K. O fator $\mathrm{R}^{2}$ que avalia a qualidade da regressão foi muito próximo ao valor máximo de 1 em todos os casos.

* Contribuição técnica ao 45 Seminário de Aciaria - Internacional, 25 a 28 de maio de 2014, Porto Alegre, RS, Brasil. 

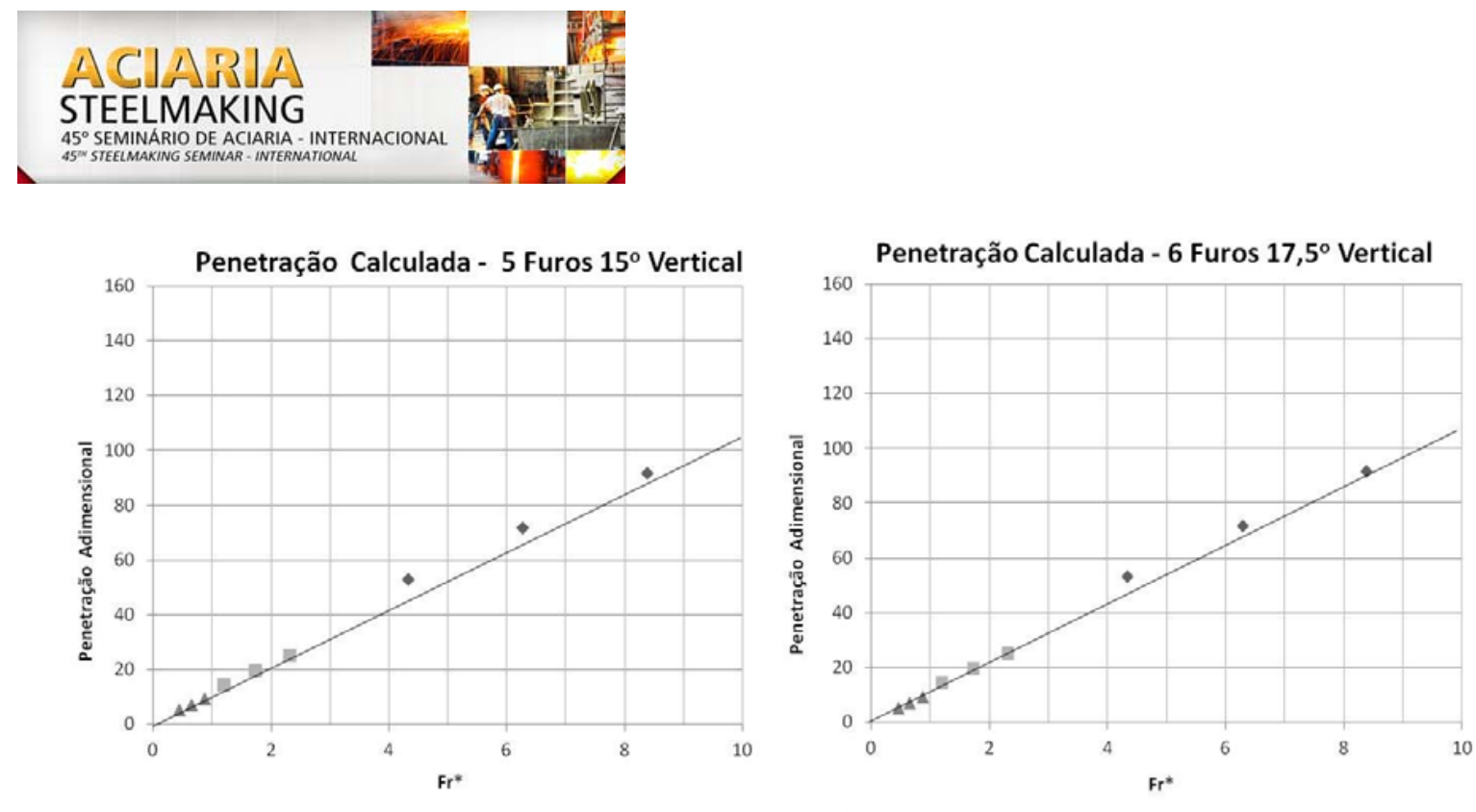

- Altura Lança $=0,117 \mathrm{~m}$ = Altura Lança $=0,180 \mathrm{~m} \quad \Delta$ Altura Lança $=0,250 \mathrm{~m}$

- Altura Lança $=0,117 \mathrm{~m} \quad$ in Altura Lança $=0,180 \mathrm{~m} \quad \Delta$ Altura Lança $=0,250 \mathrm{~m}$

Figura 12. Penetração adimensional versus Froude modificado para bicos de 5 e 6 furos, vazões de $100 \mathrm{Nm}^{3} / \mathrm{h}, 130 \mathrm{Nm}^{3} / \mathrm{h}$ e $160 \mathrm{Nm}^{3} / \mathrm{h}$ e DBL de $0,110 \mathrm{~m}, 0,180 \mathrm{~m}, 0,250 \mathrm{~m}$.

$\mathrm{Na}$ Tabela 2 constam as constantes "K" obtidas.

Tabela 2. Coeficientes angulares das retas de penetração adimensional versus número de Froude

\begin{tabular}{|c|c|c|c|}
\hline Furos & Ângulo Vertical & $\mathrm{K}$ & $\mathrm{R}^{2}$ \\
\hline 3 & $7^{\circ}$ & 5,769 & 0,996 \\
\hline 4 & $12^{\circ}$ & 5,042 & 0,995 \\
\hline 5 & $15^{\circ}$ & 4,663 & 0,998 \\
\hline 6 & $17,5^{\circ}$ & 4,418 & 0,995 \\
\hline
\end{tabular}

Os coeficientes angulares encontrados representam parâmetros de transferência dos resultados obtidos em escala laboratorial para a escala industrial dado um determinado número de furos do bico de sopro. Por mais que as características dos fluidos e as condições operacionais sejam distintas, todos os parâmetros da Equação 1 são conhecidos, exceto o valor de "K" e da penetração do jato. Em trabalhos realizado com bicos de 04 furos e ângulos de torção, Maia et al. [12] encontrou valores médios de 4,95 $\pm 0,51$, sendo a principal diferença ângulos em relação a vertical e geometria do bocal e Meidani et al. [2] valores entre 9,8 e 12 para bocais únicos com proteção de jato.

\subsection{Avaliação da Bacia de Descarburação}

O impacto do jato supersônico de ar com o banho de água causa a formação de uma bacia de mistura, que provoca turbidez da água, ao longo de toda a área da superfície do banho na qual ele atinge. O volume desta bacia é definido pela penetração máxima atingida pelo sopro e pela área sobre a qual o sopro se distribui imediatamente acima da superfície. Estas duas medidas por sua vez, são intimamente dependentes do tipo de bico utilizado. Bicos com maior número de furos distribuem o sopro sobre uma área maior, mas perdem em penetração. Bicos com menor número de furos concentram o sopro, mas atingem maiores penetrações. Tomando-se os mesmo instantes analisados para o cálculo de penetração máxima, utilizou-se o software ImageJ® para cálculo da área superficial das bacias de misturas, devido ao contraste formado pela turbidez, conforme o exemplo da Figura 5. As medidas foram utilizadas como estimativa da fração volumétrica ocupada do banho em cada condição de sopro, conforme apresentado na Figura 13.

* Contribuição técnica ao $45^{\circ}$ Seminário de Aciaria - Internacional, 25 a 28 de maio de 2014, Porto Alegre, RS, Brasil. 


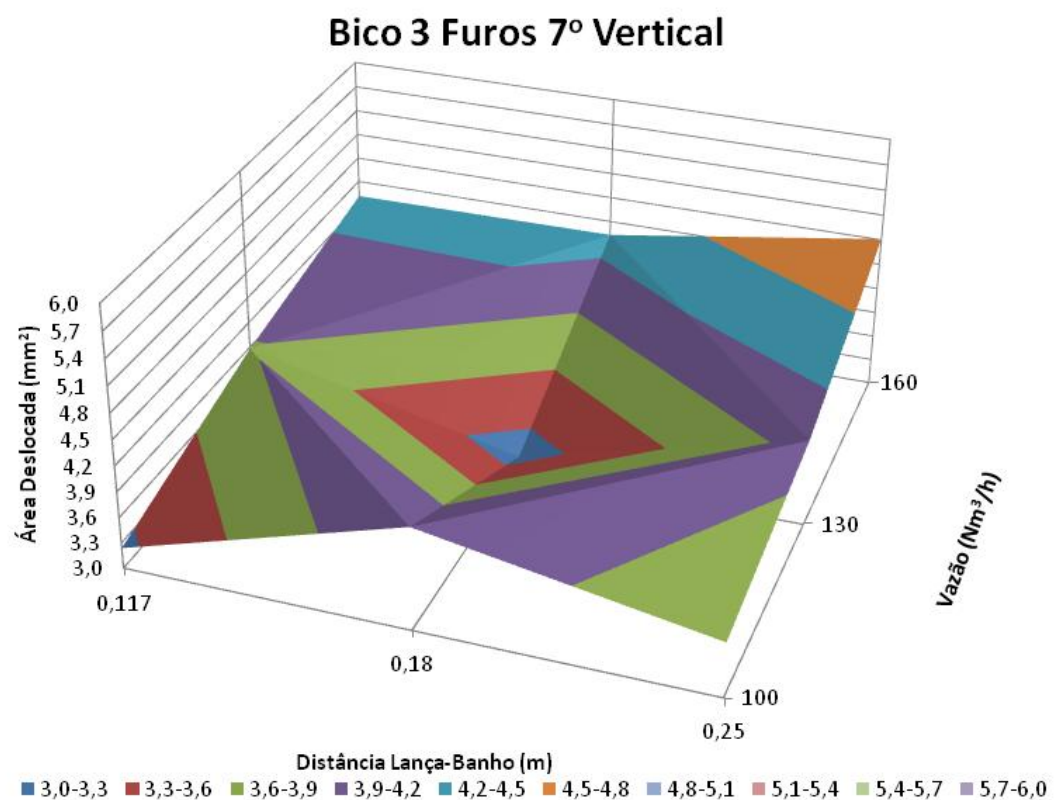

Figura 13. Área superficial medida da bacia de turbidez para bicos de 3 furos e $7^{\circ} \mathrm{com}$ vertical, para todas a vazões e alturas de lança testadas.

Para o bico de 3 furos e $7^{\circ} \mathrm{com}$ a vertical, a vazão elevada associada com a altura elevada promoveram a maior área de mistura, decorrente da aumento da área projetado dos jatos sobre a superfície do banho. Devido ao pequeno ângulo e número de furos, esse bico tem características de elevada penetração, porém quando combinados valores intermediários de vazão e altura de lança, foram obtidos os menores valores de área movimentada. A Figura 14 apresenta a área de mistura para um bico com 4 furos e ângulo de $12^{\circ} \mathrm{com}$ a vertical.

\section{Bico 4 Furos $12^{\circ}$ Vertical}

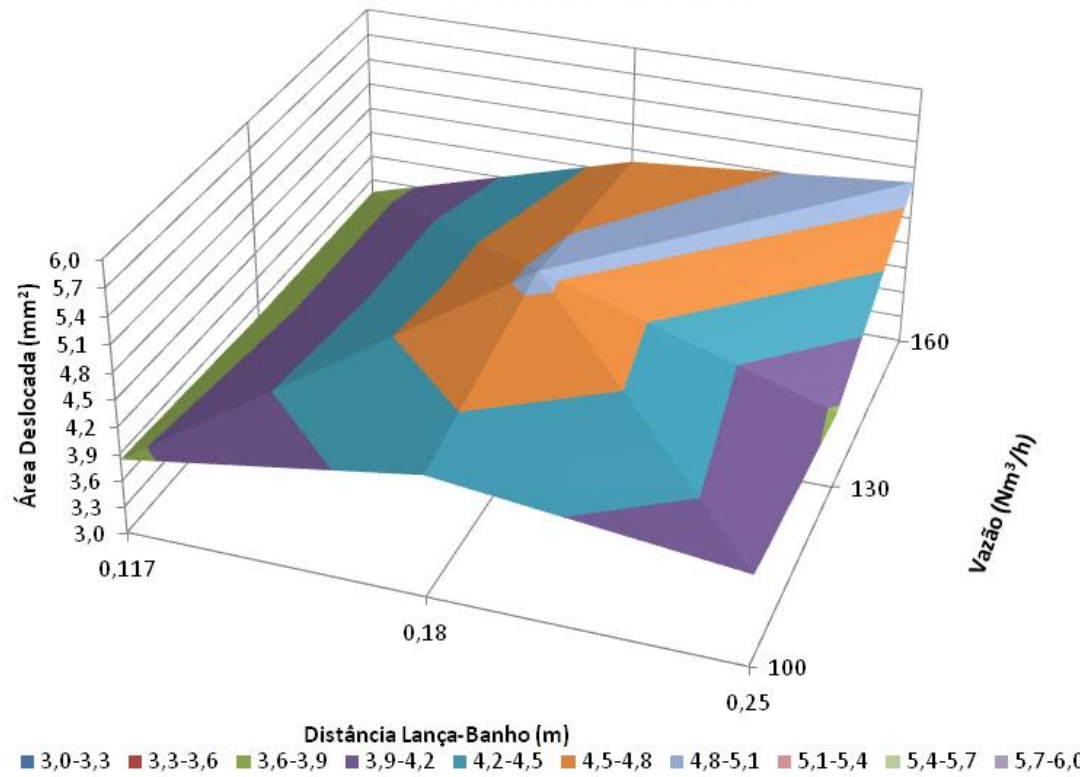

Figura 14. Área superficial medida da bacia de turbidez para bicos de 4 furos e $12^{\circ} \mathrm{com}$ vertical, para todas a vazões e alturas de lança testadas.

Na Figura 14, com o aumento do número de furos, as menores áreas de misturas foram obtidas para a mais altura de lança, $0,117 \mathrm{~m}$. Baixas vazões também

* Contribuição técnica ao 45 Seminário de Aciaria - Internacional, 25 a 28 de maio de 2014, Porto Alegre, RS, Brasil. 
contribuem para esse efeito. À medida que altura de lança é elevada ocorre um aumento significativo da área de mistura. O mesmo ocorre com o aumento da pressão. Hipótese levantada é a existência de uma altura de transição entre características de penetração e área de mistura. A Figura 15 apresenta a área de mistura para um bico com 5 furos e ângulo de $15^{\circ} \mathrm{com}$ a vertical.

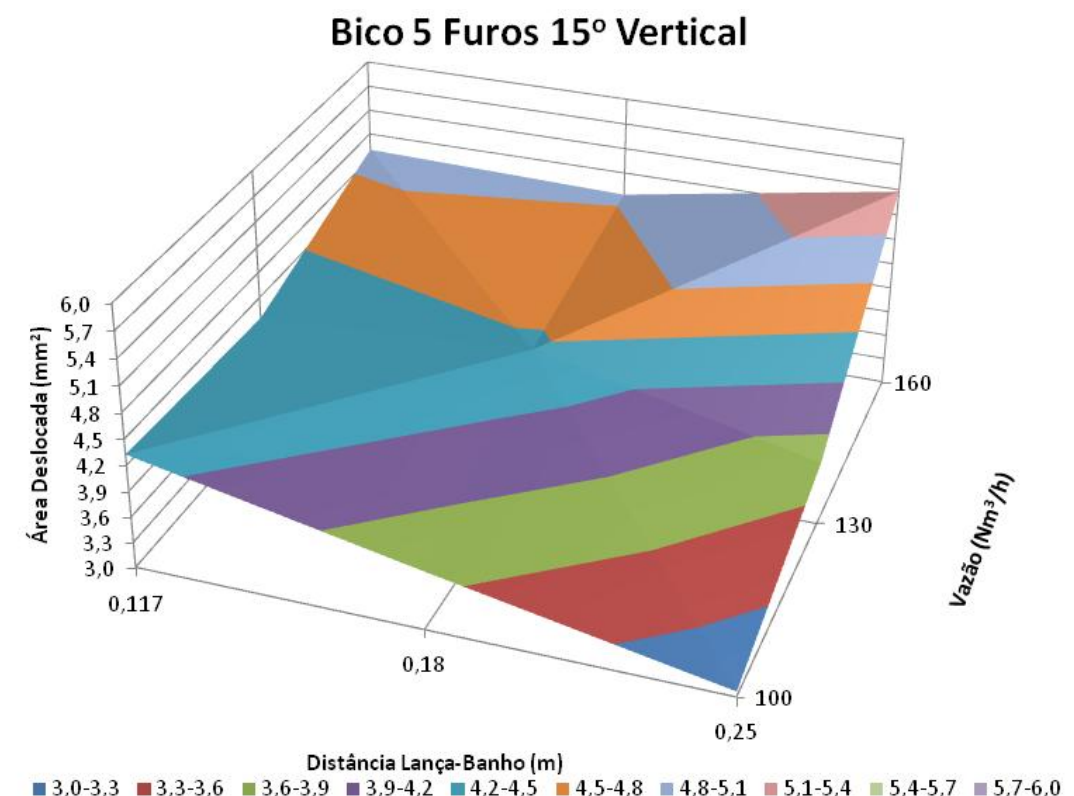

Figura 15. Área superficial das bacias de turbidez para bicos de 5 furos e $15^{\circ} \mathrm{com}$ vertical, para todas a vazões e alturas de lança testadas.

Na Figura 15, o aumento da área de mistura aparenta ser diretamente proporcional a vazão e inversamente proporcional a altura de lança. Devido ao aumento no número de furos a hipótese levantada é a melhor distribuição dos jatos sobre a superfície do banho do metálico associado com o aumento do ângulo. A Figura 16 apresenta a área de mistura para um bico com 6 furos e ângulo de $17,5^{\circ} \mathrm{com}$ a vertical.

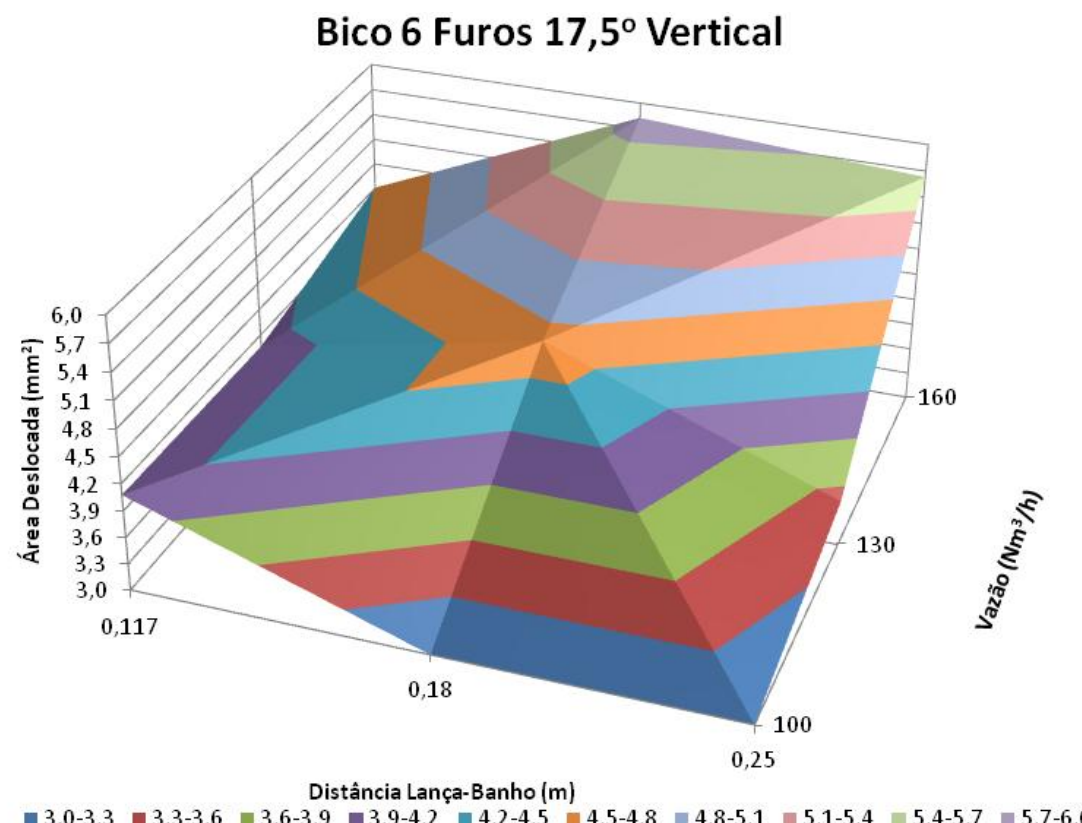

Figura 16. Área superficial das bacias de turbidez para bicos de 6 furos e $17,5^{\circ}$ com vertical, para todas a vazões e alturas de lança testadas.

* Contribuição técnica ao 45 Seminário de Aciaria - Internacional, 25 a 28 de maio de 2014, Porto Alegre, RS, Brasil. 
Na Figura 16, para bico de 6 furos e ângulo de 17,50 com a vertical, novamente repete o comportamento de aumento proporcional da área da mistura com a vazão e inversamente proporcional a altura de lança, porém a diferença está no aumento dessa área quando comparado com os máximos valores encontrado para o bico de 5 furos e ângulo de $15^{\circ} \mathrm{com}$ vertical.

As maiores áreas medidas foram obtidas para a vazão máxima de $160 \mathrm{Nm}^{3} / \mathrm{h}$, para a DBL de 0,180m. Os resultados com 3 e 4 furos, que, apesar de alcançarem as maiores penetrações, não possuíram área superficial suficiente para formação de uma bacia de mistura considerável.

\section{CONCLUSÃO}

Foram tiradas as seguintes conclusões sobre a penetração do jato utilizando bicos multifuros:

1. Maiores vazões implicam maiores penetrações tanto para bicos quanto distâncias variadas.

2. Bicos com maior número de furos causaram redução na penetração do jato devido ao aumento na distribuição de sua energia sobre a superfície do banho, dada mesmas vazão e DBL.

3. As menores distâncias banho-lança fornecem maiores penetrações. Com 5 e 6 furos, o efeito do aumento da distância sobre a penetração foi mais evidente, de forma que a uma distância de $0,250 \mathrm{~m}$ o jato praticamente não penetrou o banho.

4. As configurações de sopro utilizando bicos de 3 e 4 furos alcançaram o fundo do modelo em quase todas as combinações ensaiadas, sinalizando uma condição operacional agressiva ao reator.

5. Bicos com 5 e 6 furos utilizados com vazão e DBL intermediários $(0,180 m$ e $130 \mathrm{Nm}^{3} / \mathrm{h}$ ) apresentaram penetração considerável mas sem atacar o fundo do modelo.

Acerca da análise das áreas das bacias de mistura, chegou-se ás seguintes conclusões:

1. Existe uma altura de transição entre o comportamento de elevada penetração e área de mistura em função do número de furos e ângulo em relação a vertical;

2. A distância banho-lança influência o comportamento predominante no banho principalmente para bicos com ângulos mais fechados;

3. O aumento do número de furos e ângulo com a vertical aumenta a bacia de mistura;

4. As maiores áreas da bacia se configuraram quando utilizada a vazão máxima $\left(160 \mathrm{Nm}^{3} / \mathrm{h}\right)$, para as mesmas distâncias e número de furos.

5. A maior área da bacia de descarburação foi obtida com a configuração de sopro de 6 furos, distância banho-lança de 0,180m e vazão de $160 \mathrm{Nm}^{3} / \mathrm{h}$.

O presente trabalho permite uma continuidade nas aciarias correlacionando alterações dos parâmetros apresentados e resposta das variáveis de processo, permitindo ajustes metalúrgicos no processo de refino do aço.

\section{Agradecimentos}

Os autores agradecem a Universidade Federal de Minas Gerais pelas as dependências do Laboratório de Simulação de Processos e insumos para a

* Contribuição técnica ao 45 Seminário de Aciaria - Internacional, 25 a 28 de maio de 2014, 
realização dos ensaios, a Lumar Metals pelo incentivo a pesquisa continuada, FAPEMIG pelo apoio financeiro concedido ao projeto PROCESSO No. : TEC - APQ00373-11 - "Modelamento físico e matemático do escoamento multifásico em sistemas metalúrgicos e Capex/Proex".

\section{REFERÊNCIAS}

1 Araújo LA. Manual de siderurgia. Vol. 1. São Paulo: Editora Arte e Ciência; 2005. p.470.

2 Meidani ARN, Isac M, Richardson A, Cameron A, Guthrie RIL. Modeling shrouded supersonic jets in metallurgical reactor vessels. ISIJ International. 2004;44(10):1639-45.

3 Maia BT. Modelamento físico e matemático do escoamento de fluidos nos processos BOF e EOF [Tese doutorado em Engenharia Metalúrgica]. Belo Horizonte: Escola de Engenharia da UFMG; 2013. p.238.

4 Odenthal $\mathrm{HJ}$, Emling WH, Kempken J, Schluter J. Advantageous numerical simulation of the converter blowing process. In: AISTech Proceedings; 2007; Pittsburg, EUA. Warrendale: AIST; 2007.

5 Rizzo SEM. Introdução aos processos de refino primário dos aços nos convertedores a oxigênio [Capacitação técnica em processos siderúrgicos: aciaria]. São Paulo:

Associação Brasileira de Metalurgia e Materiais; 2006. p.118.

6 Barbosa FA. Modelamento matemático e físico do escoamento do aço líquido em diferentes projetos de distribuidor do lingotamento contínuo da Usiminas [Dissertação mestrado em Engenharia Metalúrgica]. Belo Horizonte: Escola de Engenharia da UFMG; 2002. p.188.

7 Carneiro FL. Análise dimensional e teoria da semelhança e dos modelos físicos. $2^{\mathrm{a}}$ ed. Rio de Janeiro: Editora UFRJ; 1996.

8 Szekely J, Themelis NJ. Rate phenomena in process metallurgy. 1 ed. Montreal: John Wiley \& Sons; 1971. p.784.

9 Alam M, Irons G, Brooks G, Fontana A, Naser,J. Inclined jetting and splashing in electric arc furnace steelmaking. ISIJ International; 2011;51(9):1439-47.

10 Alam M, Naser J, Brooks G, Fontana A. Computational fluid dynamics modeling of supersonic coherent jets for electric arc furnace steelmaking process. Metallurgical and Materials Transactions B. 2010;41B:1354-67.

11 Alam M, Naser J, Brooks G, Fontana A. Computational fluid dynamics simulation of supersonic oxygen jet behavior at steelmaking temperature. Metallurgical and Materials Transactions B. 2010;41B:636-45.

12 Maia BT, Faustino RA, Abreu G, Costa B, Tavares RP. Efeitos dos parâmetros de sopro no tempo de mistura utilizando modelo físico de convertedor. In: ABM. Anais do 44ํ Seminário de Aciaria - Internacional; 2013; Araxá, Minas Gerais. São Paulo: ABM; 2013.

* Contribuição técnica ao 45 Seminário de Aciaria - Internacional, 25 a 28 de maio de 2014, 